\title{
Um estudo das potencialidades das Tecnologias de Informação e Comunicação, na concepção de alunos e professores de ciências naturais do Município de Macaíba/RN
}

\author{
Kelvin Vinicius de Almeida Alves ${ }^{1}$, Airton Araujo de Souza Junior ${ }^{2}$ \\ ${ }^{1}$ Instituto Federal de Educação, Ciência e Tecnologia do Rio Grande do Norte \\ Rua Antônia de Lima Paiva, $n^{\circ} .155$ - Bairro Nova Esperança - Parnamirim - CEP \\ $59143-455$ \\ ${ }^{2}$ Universidade Federal do Rio Grande de São Paulo (Unifesp) \\ Rua Sena Madureira, no. 1.500 - Vila Clementino - São Paulo - SP - CEP 04021-001 \\ kelvinoms@hotmail.com, airton.junior@ifrn.edu.br
}

\begin{abstract}
Discussions about the inclusion of Information and Communication Technologies (ICT) in the school setting are increasingly increasing, due to the great importance of this resource as an instrument in the teaching-learning process. Thus, this qualitative research consists of analyzing the potential of ICTS in the conception of some science teachers and students of the elementary school in the City of Macaiba/RN. The results show that some teachers and students have innovative conceptions and Believe that the same The use of technological resources can help the activities coming from school everyday.
\end{abstract}

Resumo. As discussões acerca da inclusão das Tecnologias de Informação e Comunicação (TICs) no cenário escolar são cada vez mais crescentes, devido à grande importância desse recurso como instrumento no processo de ensinoaprendizagem. Assim, esta pesquisa, de cunho qualitativo, consiste em analisar as possíveis potencialidades das TICs na concepção de alguns professores de ciências e alunos do ensino fundamental do município de Macaiba/RN. Os resultados obtidos mostram que alguns professores e alunos possuem concepções inovadoras e acreditam que o uso de recursos tecnológicos podem auxiliar as atividades provenientes do cotidiano escolar.

\section{Introdução}

No mundo globalizado e informatizado no qual estamos inseridos, as relações com o conhecimento adquirem novas dimensões, em que a escola é levada a desenvolver estratégias para as novas atitudes pedagógicas das Tecnologias de Informação e Comunicação (TICs), promovendo os requisitos necessários para viver em uma sociedade em transformação (GRINSPUN,1999).

De acordo com Pereira e Freitas (2009), o aparecimento de novas tecnologias faz parte da nossa realidade atual e essas tecnologias ampliam as possibilidades do professor ensinar e do aluno aprender. Verifica-se que quando utilizadas adequadamente, auxiliam no processo educacional.

Quando essas novas ferramentas são utilizadas no âmbito escolar, tornam-se não só um facilitador na compreensão do conhecimento científico mas também um instrumento significativo no processo de ensino-aprendizagem. Nessa perspectiva, os dispositivos móveis, aliados à internet, vêm ganhando espaço no cotidiano escolar. É 
por meio deles que a interatividade ganha força na educação e favorece atividades colaborativas entre os professores e alunos.

As TICs funcionam como ferramenta facilitadora do ensino e, com seu auxílio, o aluno deixa de ser apenas um receptor no processo de aprendizagem, tornando-se um ser ativo na construção do seu próprio conhecimento. Dessa forma, como as mídias sociais e aplicativos são recursos bastante utilizados entre os alunos atualmente, o uso dessas ferramentas na educação pode favorecer a utilização de novas metodologias e estratégias em favor da aprendizagem, proporcionando possibilidades inovadoras no processo ensino-aprendizagem.

No ensino de Ciências, é notória a dificuldade do aluno em relacionar a teoria desenvolvida em sala à realidade a sua volta. Considerando que a teoria é feita de conceitos com abstrações da realidade, torna-se necessário o uso de alternativas que transcenda a teoria e a prática e que tornem o ensino de qualidade. Com isso, este trabalho ressalta as possíveis potencialidades de ampliação do uso das TICs a partir da concepção dos professores e dos alunos.

Com base nessas premissas, esta pesquisa foi desenvolvida com o objetivo de investigar a concepção de professores e alunos a respeito das TICs. Para tanto foi analisada a utilização desse recurso no ensino de ciências naturais, em escolas públicas do município de Macaíba/RN. De forma mais específica, foi averiguado qualitativamente o nível de conhecimento e de uso das TICs por professores de ciências e por alunos dos anos finais do ensino fundamental.

\section{As TICs no âmbito educacional}

Chamam-se de Tecnologias de Informação e Comunicação (TICs) os procedimentos, métodos e equipamentos para processar e comunicar informação. As TICs surgiram no contexto da Revolução Informática - também conhecida como Revolução Telemática ou Terceira Revolução Industrial -, desenvolvida gradualmente desde a segunda metade da década de 1970 e, principalmente, nos anos 90 do mesmo século (RAMOS, 2008).

Martinho (2008) afirma que as TICs podem constituir um elemento valorizador nas práticas pedagógicas, uma vez que acrescenta, em termos de acesso à informação, flexibilidade, diversidade de suportes no seu tratamento e apresentação. Valorizam, ainda, os processos de compreensão de conceitos e fenômenos diversos na medida em que conseguem associar diferentes tipos de representação, as quais vão desde o texto à imagem fixa e animada, ao vídeo e ao som.

De acordo com Kenski (2001), a tecnologia é entendida como ferramenta de transformação do ambiente tradicional da sala de aula, buscando a produção do conhecimento de forma criativa, interessante e participativa, possibilitando ao educador e educando aprenderem e ensinarem usando imagens, sons, formas textuais, e com isso adquirirem os conhecimentos necessários para a sobrevivência no dia-a-dia em sociedade.

Segundo Coll, Mauri e Onrubia (2010), as capacidades efetivas dessas tecnologias para transformar as dinâmicas de trabalho e processos de ensino e aprendizagem nas salas de aula, geralmente, ficam muito abaixo do potencial transformador e inovador que normalmente lhes são atribuídas.

$\mathrm{Na}$ tentativa de identificar e descrever os usos das TICs, Coll, Mauri e Onrubia (2010) propõem uma classificação a partir da qual as tecnologias estão sempre 
mediando relações entre partes de um "triângulo interativo" formado por professoraluno-conteúdo. Os autores ainda afirmam que o que define o tipo de uso que se dá às TICs é sua posição na rede de relações que se estabelecem entre os três elementos do triângulo interativo.

O grande desafio de se aplicar as TICs à educação é fazer com que as inovações tecnológicas realmente melhorem a qualidade do ensino e não se tornem apenas ferramentas obsoletas e sem adequação ao processo de ensino-aprendizagem (CYSNEIROS, 1999).

Os desafios se iniciam na estrutura das escolas: adequação dos espaços físicos, aquisição de equipamentos tecnológicos e promoção da manutenção; e na preparação dos profissionais: fornecimento de meios para sua capacitação, motivação e inovação metodológica. Sobre esses desafios, Castells (2003) salienta que "a escola precisa formar pessoas com potenciais muito flexíveis, que mudem, transformem e transitem em diversas situações, experiências e contextos". Dessa maneira, é importante que as escolas estejam preparadas para inclusão das novas tecnologias, para que seja viável a utilização desse recurso como um suporte de ensino e aprendizagem.

\section{Os dispositivos móveis e o ensino de ciências}

Conforme Pereira (2014), o ensino de ciências proporciona aos alunos uma visão mais crítica de fatos e fenômenos relacionados ao seu dia a dia, além de uma interação maior com as diversidades, sejam elas culturais, sociais e/ou científicas, o que faz com que sejam "inúmeros os avanços científicos mediados pelos recursos tecnológicos, inclusive àqueles ligados às tecnologias da informação e comunicação"

O desenvolvimento das TICs contribui para subsidiar novas formas de obtenção do conhecimento, que podem ser usadas adequadamente com o contexto do assunto estudado, abrindo novas possibilidades na aprendizagem das Ciências (COSTA; OLIVEIRA, 2012). Nesse sentido, Moran (2009) assegura que "é fundamental que não nos esqueçamos de que a tecnologia possui um valor relativo: ela somente terá importância se for adequada para facilitar o alcance dos objetivos que se pretende alcançar, ou seja, a aprendizagem”.

No que concerne às TICs, as tecnologias digitais (TD), associadas às tecnologias móveis e sem fio, têm proporcionado o surgimento de novos espaços para o processo de ensino e aprendizagem, não se restringindo apenas ao âmbito da escola, mas, sobretudo, auxiliando no acesso à informação em qualquer lugar, como é o caso do celular, do tablet, entre outros dispositivos portáteis (SANTOS; CLEOPHAS, 2015).

Para Saboia, Vargas e Viva (2013), os dispositivos móveis vêm sendo utilizados nas mais diversas áreas. Essa utilização tem se expandido, pois há uma natural evolução social em que as gerações anteriores têm se apropriado cada vez mais dessas tecnologias, e as novas gerações, agora consideradas "nativos digitais", já incorporam tais dispositivos como uma extensão do lar ou de seu próprio corpo.

Segundo Prensky (2001), os jovens estão acostumados a obter informações de forma rápida e costumam recorrer primeiramente a fontes digitais e à internet antes de procurarem em livros ou na mídia impressa. Por causa desses comportamentos e atitudes, e por entender a tecnologia digital como uma linguagem, Prensky (2001) os descreve como "nativos digitais", uma vez que "falam" a linguagem digital desde que nasceram.

Em suma, e segundo Santos (2007), os principais benefícios do uso das TICs no 
ensino das ciências são: (i) o ensino das ciências torna-se mais interessante, autêntico e relevante; (ii) há mais tempo dedicado à observação, à discussão e à análise e (iii) existem mais oportunidades para implementar situações de comunicação e colaboração.

\section{Metodologia}

O presente trabalho seguiu uma abordagem qualitativa, configurando-se, portanto, como uma pesquisa do tipo descritiva. Para Gil (2008), a pesquisa qualitativa tem caráter investigatório e faz emergir aspectos subjetivos e espontâneos do entrevistado.

Participaram desta pesquisa professores e alunos do município de Macaíba/RN. No total, doze professores de ciências interessaram-se e se propuseram a colaborar com o estudo, no qual onze deles possuem Licenciatura em Ciências Biológicas e apenas um professor possui o magistério. Esses colaboradores são oriundos de 10 escolas da rede municipal de ensino, distribuídas na zona rural e zona urbana do município. Apenas professores de Ciências puderam colaborar com a pesquisa, uma vez que a o estudo foi direcionado para a área das ciências naturais.

Além dos 12 professores, participaram 120 alunos dos anos finais do ensino fundamental ( $6^{\circ}$ ao $9^{\circ}$ ano), provenientes do Centro Educacional Vereador Pedro Gomes de Souza, localizado também no município Macaíba/RN. Essa escola foi escolhida para coleta de dados dos alunos, por se caracterizar como a escola com o maior Índice de Desenvolvimento da Educação Básica (IDEB) do Município no ano de 2015, além de possuir uma boa localização no centro da cidade.

A identificação tanto dos professores quanto dos alunos foi preservada, com o propósito de deixá-los mais a vontade com relação à construção de suas respostas.

Para tanto, a fim de coletar os dados dos professores, foi aplicado um questionário virtual, por meio do formulário de pesquisa do Google (Google Forms), composto por nove questões, nas quais seis delas caracterizam-se como questões fechadas, com o intuito de traçar um perfil dos professores em relação ao uso das TICs durante suas aulas. Aliado a isso, as outras três questões foram abertas, com a intenção de conhecer a melhor metodologia escolhida pelos professores perante as situações descritas nas questões.

Para a coleta de dados dos alunos, foi aplicado um questionário impresso contendo cinco questões. Quatro dessas questões foram fechadas, na intenção de conhecer o grau de conhecimento e utilização das TICs por parte dos alunos, e uma questão aberta, questão essa utilizada no questionário dos professores, no intuito de identificar as divergências e convergências entre a melhor maneira de aplicar metodologias dos professores e a melhor forma de aprender dos alunos.

Em todas as questões abertas dos questionários foi utilizado o método de evocação de palavras, que consiste em responder a questão evocando palavras relacionadas com a situação descrita na questão. Esse método faz parte de uma adaptação simplificada do método de esquemas cognitivos de base (ROUQUETTE, 1994), com o objetivo de obter uma especificação mais fina de diferentes relações de termos evocados.

\section{Análise dos dados}

Após a análise e a interpretação dos dados coletados nos questionários, foi possível 
traçar um perfil dos professores e dos alunos entrevistados. A faixa etária dos professores entrevistados variou entre 24 e 55 anos de idade, já a faixa etária dos alunos variou entre 11 e 18 anos de idade. Com relação aos entrevistados, notou-se que grande parte está familiarizada com as atuais mudanças da tecnologia, o que proporciona novos caminhos para uma aprendizagem mais significativa, além também do aperfeiçoamento das metodologias vigentes.

Com base nisso, a informação adquirida por meio dos aparatos tecnológicos oferece alternativas efetivas aos educadores para auxiliá-los no processo de ensinoaprendizagem. Deve-se, portanto, garantir que essa "revolução digital" torne-se uma ferramenta educacional, uma vez que cria novas possibilidades, capacidades de pesquisa e poder de criação (RODRIGUES, 2015).

Essa perspectiva é confirmada pelos professores entrevistados, pois $75 \%$ deles afirmam que usam o celular para planejar as aulas e que esse dispositivo pode ser utilizado como um suporte metodológico na prática docente, uma vez que contribui e facilita no momento do planejamento de ensino. Entretanto, $25 \%$ dos entrevistados não utilizam o celular como recurso metodológico.

Apesar de os professores usarem o celular tanto para planejar quanto como suporte metodológico, observa-se que o perfil do aluno é diferente, pois $75 \%$ dos alunos afirmam que não utilizam o dispositivo móvel como um recurso para auxiliar em seus estudos, enquanto apenas $25 \%$ fazem esse uso. Porém, $60 \%$ dos alunos acreditam que o celular é um dispositivo que pode auxiliar a compreensão e a assimilação de novos conceitos, enquanto $40 \%$ discordam da capacidade do celular em auxiliar os estudos.

Após o diagnóstico do potencial de utilização dos dispositivos móveis, foi analisado o uso da internet. Para Ramos e Coppola (2009), a internet é hoje uma ferramenta indispensável no processo de ensino-aprendizagem, pois ela proporciona uma interação efetiva entre professores e alunos, possibilitando, assim, novas propostas de trabalho. Ela consegue fazer uma ponte entre a escola e o mundo exterior, aumentando, dessa forma, a comunicação entre a escola, os alunos, os pais e toda a comunidade. Ademais, proporciona um trabalho mais divertido, por meio da internet o aluno deixa de ser um mero receptor e passa a fazer parte ativamente do processo de ensino-aprendizagem.

Desse modo, foi observado que aproximadamente $92 \%$ dos professores relatam que a escola onde trabalham possui internet, porém a rede não é de boa qualidade. Segundo Ramos e Coppola (2009), esse fato implica diretamente na autonomia dos alunos em realizar pesquisas, uma vez que ensinar com o auxílio da internet derruba as barreiras de sala de aula, acelerando a autonomia de aprendizado dos estudantes em seus próprios ritmos, assim a educação assume um caráter coletivo.

Após avaliar a infraestrutura da internet, foi analisado o perfil do uso das mídias sociais. De acordo com os alunos que participaram da pesquisa, as redes sociais mais utilizadas para auxiliar os estudos são, em ordem de relevância: o Youtube, Google+, Whatsapp, Facebook e Skype. Não obstante, segundo os professores, as redes sociais funcionam como um amparo tecnológico que facilitam o alcance dos objetivos presentes no planejamento de ensino. Assim como os alunos, os professores utilizam algumas redes sociais, como: Youtube, Whatsapp, Facebook e Google+.

Esse resultado está em consonância com o que analisam Bezerra e Brito (2013), os autores afirmam que, para a educação, a utilização de tecnologias digitais pode promover a democratização do ensino e a propagação do conhecimento, além de conferir interatividade e flexibilidade no ritmo de estudo. Dessa maneira, as redes 
VI Congresso Brasileiro de Informática na Educação (CBIE 2017)

Anais do XXIII Workshop de Informática na Escola (WIE 2017)

sociais têm ampliado as possibilidades de inovação e aprendizado por meio do seu poder de compartilhamento.

Com isso, foi também avaliada a utilização de diversos tipos de aplicativos voltados para a simplificação das tarefas do planejamento de ensino por parte dos professores. Os aplicativos Edmodo, Attendance e Evernote foram os mais mencionados, como mostra o gráfico 1. No entanto, 41,7\% dos professores entrevistados nunca utilizaram nenhum desses aplicativos como suporte para a sua prática pedagógica.

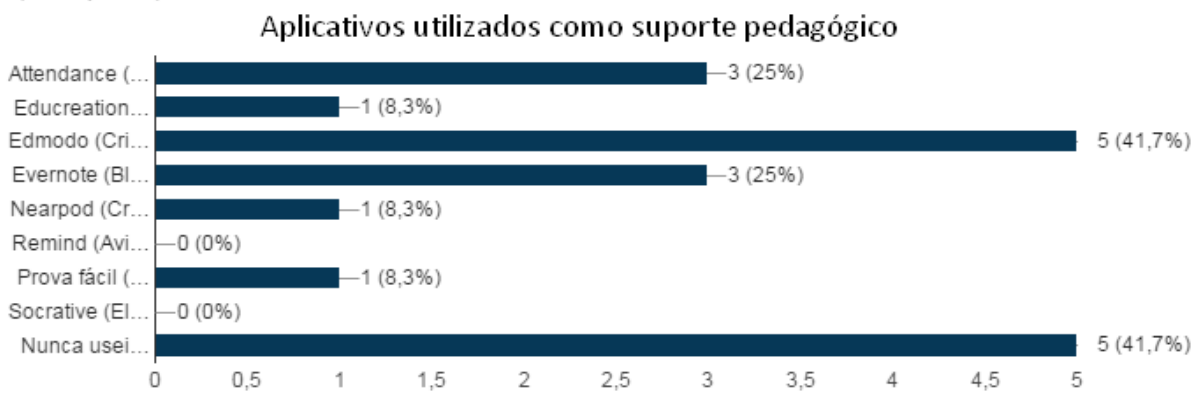

Gráfico 1: Aplicativos mais utilizados pelos professores.

Esses resultados são ratificados pela discussão de Freitas (2016), em seu trabalho sobre a influência do aplicativo de celular no processo de ensino e aprendizagem, ele afirma que as tecnologias trouxeram outras perspectivas para o ensino nas escolas. Hoje a grande maioria delas buscam novas práticas pedagógicas disponíveis por meio de aplicativos educacionais. Os meios tecnológicos estão presentes no cotidiano dos alunos e, de uma maneira ou outra, eles têm acesso, seja no uso do celular, computadores, em casa ou na escola.

Nas questões abertas, foi adotado o método de evocação de palavras, no qual, a partir das situações expostas, os professores tiveram a oportunidade de mencionar palavras, com o intuito de atender o problema de cada questão.

A partir da evocação de palavras, foi possível construir nuvens de palavras para expressar os dados das questões, por meio do programa Word Cloud. No método de nuvens de palavras, cada palavra tem seu tamanho regido pela relevância de repetições, ou seja, as palavras que foram citadas mais vezes terão tamanho maior na nuvem com relação às palavras menos citadas. Dessa forma, os professores se depararam com três situações diferentes explicitas no quadro 1.

Quadro 1: Situações das questões abertas do questionário

Situação 1
- Você é o professor de
ciências de uma escola da
rede pública de ensino no
Brasil. Para atingir alguns dos
objetivos propostos no seu
plano de ensino, você planeja
uma aula sobre células. No
decorrer do seu
planejamento, você nota que
esse conteúdo é algo muito
abstrato, então recorre para
o uso de ilustrações para
facilitar a compreensão dos
seus alunos. Com base
nessa situação, evoque 3
palavras-chaves que em sua
opinião auxiliariam a situação
descrita.
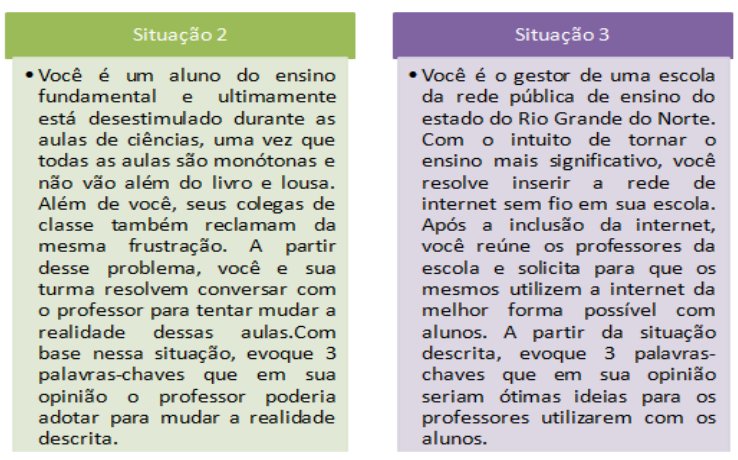

Com o objetivo de saber se os professores resolveriam as situações com o auxílio das TICs, o método de nuvens de palavras foi escolhido, por ser um instrumento 
VI Congresso Brasileiro de Informática na Educação (CBIE 2017)

Anais do XXIII Workshop de Informática na Escola (WIE 2017)

dinâmico e atrativo para a análise dos dados.

Como exposto na figura 1, a seguir, na situação 1 (quadro 1) os professores deveriam tentar resolver o problema da dificuldade de compreensão do conteúdo de células com ilustrações. São inúmeros os recursos que ajudariam os professores, no entanto, a nuvem de palavras (figura 1) expõe que a opção eleita pelos professores é a utilização de vídeos, seguida de slides e do recurso Youtube.

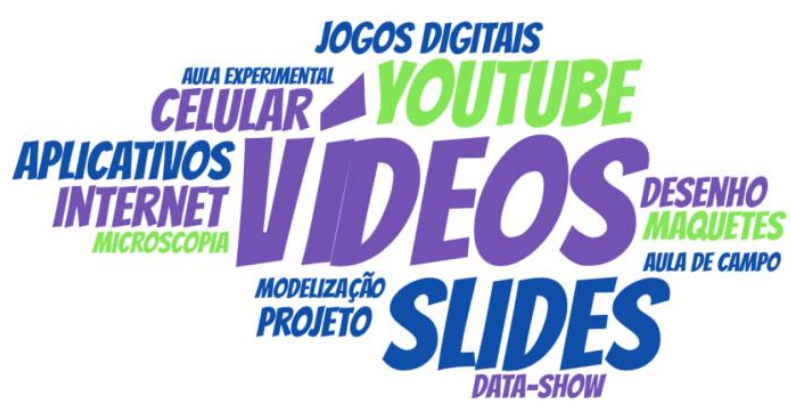

Figura 1: Nuvem de palavras construída a partir das respostas dos professores perante a situação 1 .

Já na situação 2 (quadro 1), os professores entrevistados deveriam se colocar na posição dos alunos e tentar ajudar seu professor na promoção de novas metodologias de ensino, mudando, assim, a realidade precária das aulas de ciências. Conforme a nuvem de palavra (figura 2), a estratégia preferida pelos professores é, novamente, a utilização de vídeos, seguido de jogos e dinâmicas.

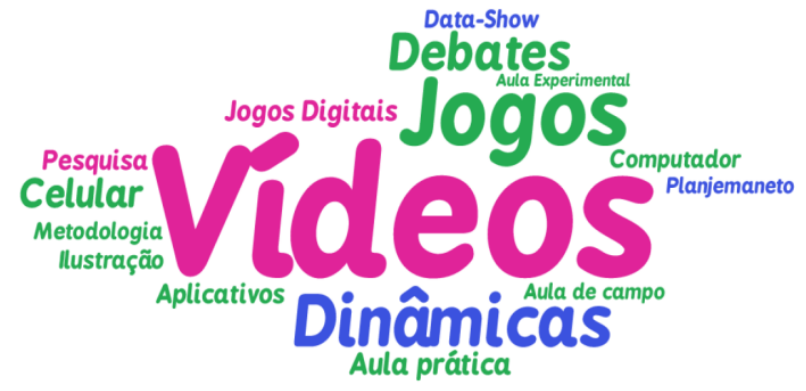

Figura 2: Nuvem de palavras construída a partir das respostas dos professores perante a situação 2.

Segundo Mychaleyko (2015), os recursos audiovisuais podem permitir diversas possibilidades pedagógicas, proporcionando um processo educativo mais dinâmico e contribuir para a autonomia do aluno em relação à construção do seu próprio conhecimento.

Nessa perspectiva, Muchenski e Beilner (2015), considerando que nos dias atuais o professor dispõe de vários equipamentos tecnológicos e que os alunos também estão imersos nesse mundo, afirma que precisamos nos valer do vídeo como recurso didático. Muitas vezes o professor tem dificuldade em contextualizar determinado conteúdo em sua disciplina, devido a sua complexidade, e o aluno dificuldade em aprender. Assim, é possível aderir a esse método para demonstrar, em um determinado contexto, sua aplicação por meio do material visual.

Partindo desse pressuposto, é fato que os alunos preferem professores dinâmicos e que variem na metodologia de ensino. Como as aulas monótonas, centradas apenas no livro didático e lousa, é uma realidade de muitas escolas do Brasil, a situação 2 (quadro 1) também foi introduzida no questionário dos alunos com a finalidade de poder conhecer os desejos dos alunos diante da luta contra as aulas com metodologias 
VI Congresso Brasileiro de Informática na Educação (CBIE 2017)

Anais do XXIII Workshop de Informática na Escola (WIE 2017)

tradicionais. Para essa análise, os resultados não contêm uma predominância de palavras evocadas, como mostra a nuvem de palavra presente na figura 3.

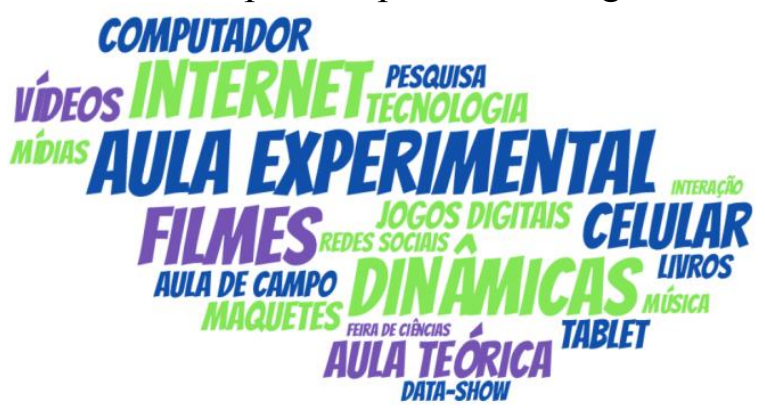

Figura 3: Nuvem de palavras construida a partir das respostas dos alunos de acordo com a situação 2.

Quando comparamos as nuvens de palavras da situação 2 (quadro 1) tanto dos professores (figura 2) quanto dos alunos (figura 3), é possível identificar ideias convergentes de metodologias e recursos que poderiam ser usados para mudar a realidade das aulas, como o uso de dinâmicas, vídeos, celular e entre outras ferramentas que tornariam as aulas mais atrativas.

Esses resultados corroboram com a ideia de Moran (2007), onde afirma que os adolescentes possuem maior facilidade de aprender quando se comunicam e se expressam por meio de dramatizações, jogos, imagens em movimento, visto que a imagem cria um conceito concreto das concepções ministradas em sala de aula.

Por fim, a situação 3 (quadro 1) revela uma realidade pouco frequente nas escolas públicas brasileiras, que é justamente o incentivo ao uso da internet, por parte da gestão escolar, em um contexto no qual, muitas vezes, as escolas são desprovidas de internet. $\mathrm{Na}$ situação proposta, os professores deveriam mencionar ideias que utilizassem a internet da melhor maneira possível com seus alunos. As redes sociais, aplicativos e simuladores foram as palavras mais evocadas, como mostra a nuvem de palavras na figura 4.

No que diz respeito aos resultados obtidos dos questionários, verificou-se que uma parte dos professores e dos alunos demonstra desconhecimento sobre as potencialidades das TICs. Para alguns professores, a dimensão apresentada por eles sobre as TICs é bastante significativa. Foi possível perceber também que, apesar de os alunos de hoje estarem adaptados aos avanços tecnológicos, muitos alunos ainda demonstram ingenuidade sobre o poder das tecnologias e de seu uso como ferramenta de estudos.

\section{Considerações finais}

No Brasil, a inserção da tecnologia na educação se revela como um potencial estratégico para romper com o atraso do aperfeiçoamento das metodologias vigentes. É importante entender que vários estudos indicam que o avanço tecnológico deve ser usado a favor da educação e servir como extensão para os professores que buscam facilitar o aprendizado e transformar o conteúdo em objeto de interesse e curiosidade dos alunos.

Com esta pesquisa, foi possível perceber que, apesar de os dispositivos móveis estarem inseridos no âmbito escolar, ainda é necessária a ampliação do uso dessas tecnologias na escola, em prol de uma aprendizagem mais significativa. Esses dispositivos se caracterizam como facilitadores do aprendizado dos alunos, pois ao 
mesmo tempo em que proporcionam aos alunos novas formas de aprender, funcionam para os professores como um suporte que promove metodologias diversificadas.

Aliado a isso, notou-se que, na concepção dos professores pesquisados, a disponibilização da internet de boa qualidade nas escolas compreende um requesito substancial no ensino contemporâneo, uma vez que podem possibilitar a pesquisa, a comunicação e o surgimento de novas formas de ensinar. A ausência da internet nas escolas pode dificultar o acesso à informação e o desenvolvimento de novas práticas pedagógicas.

Foi possível notar a familiarização de alguns professores e alunos perante as mudanças geradas pelo avanço tecnológico, no qual o uso das mídias sociais e aplicativos estão se tornando uma atividade mais presente e necessária na luta contra o ensino centrado em princípios tradicionais.

Percebe-se ainda que muitos professores e alunos possuem uma visão inovadora e recorrem ao uso de recursos tecnológicos na tentativa não só de suprir as necessidades decorrentes das situações rotineiras do cotidiano escolar como também de aperfeiçoar as metodologias vigentes. Porém, alguns professores ainda resistem à inclusão da tecnologia em sua prática pedagógica. Vale salientar também que a tecnologia não é uma solução para o aperfeiçoamento de metodologias, e sim uma ferramenta de complemento com a capacidade de motivar e melhorar o rendimento dos alunos.

Em suma, foi possível perceber que o uso das tecnologias de informação e comunicação na escola está cada vez mais presente, mas ainda falta um caminho a percorrer para que essas ferramentas - como o celular e outros recursos tecnológicos façam parte das atividades de toda comunidade escolar.

\section{Referências}

Bezerra, J. C. C., \& BRITO, S. D. O. (2013). "Redes Sociais como ferramenta pedagógica: O caso do projeto e-Jovem". In Congresso Internacional Abed de Educação a Distância.

Castells, M. (2003). "A Galáxia Internet: reflexões sobre a Internet, negócios e a sociedade". Zahar.

Coll, C.; Mauri, T.; Onrubia, J. (2010). “A Incorporação das tecnologias da informação e da comunicação na educação: do projeto técnico-pedagógico às práticas de uso". Coll et al. Psicologia da educação virtual: aprender e ensinar com as tecnologias da informação e da comunicação. Porto Alegre: Artmed.

Costa, H., \& Oliveira, I. (2012). "O uso das tecnologias no ensino das Ciências: resultados preliminares de um estudo no âmbito de cursos de natureza profissionalizante”. In II Congresso Internacional TIC e Educação (pp. 1767-1769).

Cysneiros, P. G. (1998). "Novas tecnologias na sala de aula: melhoria do ensino ou inovação conservadora". Informática Educativa, 12(1), 11-24.

Fontes, A., \& Silva, I. (2004). "Uma nova forma de aprender Ciências: a educação em Ciência/Tecnologia/Sociedade (CTS)". Porto: Edições ASA.

Freitas, J. L. (2016). "Utilização de Aplicativo de Celular para Tabuada Auxiliando no Processo de Ensino Aprendizagem". Boa Vista/RR.

Gil, A. C. (2008). "Como elaborar projetos de Pesquisa”. 4. Ed. São Paulo: Atlas. 
VI Congresso Brasileiro de Informática na Educação (CBIE 2017)

Anais do XXIII Workshop de Informática na Escola (WIE 2017)

Grinspun, M. P. S. Z., \& Rodrigues, A. M. M. (1999). "Educação tecnológica: desafios e perspectivas".

Kenski, V. M. (2001). Em direção a uma ação docente mediada pelas tecnologias digitais. Tecnologias educacionais e educação a distância: avaliando políticas e práticas. Rio de Janeiro: Quartet, 74-84.

Martinho, T. S. G. R. M. (2008). "Potencialidades das TIC no ensino das Ciências Naturais: um estudo de caso". (Master's thesis, Universidade de Aveiro).

Martins, I. P. (2002). "Problemas e perspectivas sobre a integração CTS no sistema educativo português". Revista electrónica de Enseñanza de las Ciencias, 1(1), 28-39.

Moran, J. M. (2009). "Novas tecnologias e mediação pedagógica”. Papirus Editora.

MORAN, J. M. (2007). "Como utilizar a internet na educação. Revista Ciência da Educação”. São Paulo.

Muchenski, F., \& Beilner, G. (2015). "O uso de vídeos como recurso pedagógico para o ensino de Física: uma experiência do programa Pibid no Instituto Federal Catarinense-Campus Concórdia”. Cadernos Acadêmicos, 7(1), 140-154.

Mychaleyko, T. R. (2015). "O vídeo como ferramenta pedagógica”.

Prensky, M. (2001). "Digital natives, digital immigrants part 1". On the horizon, 9(5), 16.

Pereira, B. T., \& Freitas, M. D. C. D. (2009). "O uso das tecnologias da informação e comunicação na prática pedagógica da escola". Universidade Federal do Paraná, 1381-8.

Pereira, L. S. (2014). "Ludicidade e TIC: caracterização da webquest como uma metodologia lúdica no ensino de ciências".

Ramos, S. (2008). "Tecnologias da Informação e Comunicação: conceitos básicos". Aveiro: OpenOffice Writer.

Ramos, M., \& Coppola, N. C. (2009). Uso do computador e da internet como ferramentas pedagógicas.

Rodrigues, D. M. D. S. A. (2015). "O uso do celular como ferramenta pedagógica". Porto Alegre.

Rouquette, M. L. (1994). "Une classe de modèles pour l'analyse des relations entre cognèmes". Structures et transformations des représentations sociales, 153-170.

Saboia, J., Vargas, P. D., \& Viva, M. A. (2013). “O uso dos dispositivos móveis no processo de ensino e aprendizagem no meio virtual". Revista Cesuca Virtual: conhecimento sem fronteiras, 1(1), 1-13.

Santos, A. C. D. S. P. (2007). "As TIC e o desenvolvimento de competências para aprender a aprender: um estudo de caso de avaliação do impacte das TIC na adopção de métodos de trabalho efectivos no $1^{\circ}$ ciclo do ensino básico". (Master's thesis, Universidade de Aveiro).

Santos, L. R., \& Graças Cleophas, M. (2015). "TIC e Ensino de Ciências: Qual a Opinião dos Professores sobre esta Parceria?" 